The book sets out to cover the whole subject of palaeomagnetism with the exception of measuring apparatus and techniques. Other aspects include a clear discussion of the basic theory of the magnetic properties of rocks, general features of the geomagnetic field, statistical processes used in palaeomagnetism, reversals of magnetization and intensity of the palaeogeomagnetic field. The final chapter deals with special topics such as local rotations of the crust, stratigraphical uses of reversals and the use of fossil magnetism in elucidating problems concerning the origin of igneous rocks. For good measure, we find a discussion of the hypothesis of an expanding Earth. The book ends with a reference list of palaeomagnetic results with 46 pages of explanatory notes.

The author has himself worked extensively in the subject and has made major contributions, first in England and then for 10 years in Australia where he worked out the palaeomagnetic history of that continent. With his geological and geophysical training, he is thus very well qualified to write this first admirable book on the subject.

The book has one failing and that is its price. It should be widely read as a text among geologists and geophysicists in addition to being a useful reference work, but the price is about 50 per cent higher than some recent comparable books in the earth sciences. Seven guineas seems to be too much for a book of 400 pages with no photographic plates for the first of many books to be written on this subject.

R. W. Girdler

\section{RADIATION AND MINING}

\section{Radiological Health and Safety in Mining and Milling of Nuclear Materials}

(Proceedings of the Symposium held by the International Atomic Energy Agency, in co-operation with the International Labour Organization and the World Health Organization, Vienna, 26-31 August 1963.) Vol. 1: Pp. 482. 210 Sch. ; 60s. ; 10 dollars. Vol. 2 : Pp. 562. 231 Sch. ; 66s. ; 11 dollars. (Vienna : International Atomic Energy Agency ; London: H.M. Stationery Office, 1964.)

$\mathrm{O}^{2}$ $F$ all the industries in which a hazard from ionizing radiations is involved the mining of radioactive materials must be the oldest, and this Symposium has brought together the wealth of experience and data accumulated over the years.

At 11 scientific sessions, 70 papers were presented, 18 of them in French, 4 in Russian and 3 in Spanish.

A short historical review by A. Schraub (Germany) opened the first session which then continued to deal with epidemiology. The paper by V. E. Archer et al. (United States) reported the results of a study of some non-fatal effects of uranium mining. J. K. Wagoner et al. (United States) presented a preliminary report on the mortality pattern among United States miners and millers from 1950 to 1962. Their evidence indicated an excess of respiratory cancer among miners with long term underground experience and suggested the cause is to be found in the airborne radioactive material.

Session 2 was introduced by a paper by D. A. Holaday (United States) which outlined some of the unsolved problems in uranium mining. Subsequent papers dealt with the general control of radiation hazards and health physics management in mines and processing plant in Canada, France, Spain, Japan, India and South Africa.

Toxicology was the subject of Sessions 3 and 4; the effect of the inhalation of radon received prime attention. Factors affecting the retention, translocation and excretion of radioactive particles were considered at length. Much of the content of these two sessions is relevant to places other than mines where radioactive sources are present or used.

In Sessions 5 and 6 the problems associated with the measurement of concentrations in air of radioactive dusts and gases, and the techniques employed to solve them, were discussed. The difficulties in relating environmental measurements to possible intakes of radioactive material were stressed. E. C. Hyatt (United States) confirmed what has been found in other fields, that the most accurate method at present available to determine the weighted average exposure to the total airborne uranium dust is by the use of personal samplers worn by the worker.

P. Pellerin et al. (France) described a practical method for systematically evaluating the radioactivity in the air of mine galleries. It consisted of measuring immediately the activity of the active deposit of the daughter products of radon-222 fixed on solid or liquid aerosols in suspension. in the atmosphere of the galleries. Samples are taken in series by suction on fixed filters which are then rapidly centralized. The threshold sensitivity of the counts was said to be of the order of $100 \mathrm{pc} . / \mathrm{m}^{3}$ air.

These Sessions showed that further work is necessary to dovelop firm numbers for threshold limit values for radon and radon daughters.

The technical problems of radiological protection formed the subject of Session 7. R. Avril and J. Pradel (France) described the precautions applied in French uranium mines where the emphasis is placed on rigid environmental control rather than the use of personal protective devices. These include the hermetic sealing of unused galleries, elimination of infiltrating water, provision of powerful ventilation and the customary dust-prevention techniques. E. C. Hyatt (United States) gave comprehensive details of a respirator programme for uranium mills and described the types available, their advantages and limitations, methods of testing and the factors involved in their selection for use. He stressed that although respirators can play an important protective part, the control of the dust at source should be the primary consideration.

In the discussion following the paper by J.A. Northcott (United States) on dust prevention in nuclear material mining, N. Chesnokov (U.S.S.R.) gave details of the precautions required in mines in the U.S.S.R. He reported that wet drilling is compulsory and that a simple throwaway type of respirator was normally worn. Unfortunately details were not given of the efficiency of filtration of these respirators, which would have been useful, particularly as a very low breathing resistance of $2-3 \mathrm{~mm}$ water was quoted.

Session 8 surveyed the subject of the management of radioactive waste. Four papers were presented which reported the studies made in the United States, Japan, France and Yugoslavia on the production of waste and its influence on the environment.

Monitoring programmes in mines, mills and the environment were reported in Session 9 . D. R. Rushing, W. J. Garcia and D. A. Clark (United States) described the methods they had found to be satisfactory for analysing: (a) effluents and environmental samples from uranium mills; (b) biological samples for radium, polonium and uranium. E. C. Tsivoglou (United States) outlined the control programme which has resulted from water monitoring near uranium mills. The monitoring was mainly for radium-226 with determinations of uranium and strontium-90 when desirable. G. Michon (France) had considered the possible contamination of milk in the area of uranium mines and processing plant, but concluded that, at least in respect of the area in France he studied, the contamination of milk did not constitute a hazard to the local population.

Medical supervision, including the criteria to be taken into account for medical examinations and the assessment of internal contamination, was included in Session 10. Five papers described urine estimation for lead-210, polonium, uranium and thorium. A device to measure radon in the breath was also described.

The final session consisted of three papers which outlined the safety regulations and standards in France, the United States and Australia.

The discussions following the papers are well reported and the production of the two volumes is up to the usual high standard of the International Atomic Energy Agency.
I. K. LEGGE 